October 2003

\title{
Candida esophagitis: Risk factors in non-HIV population in Pakistan
}

Javed Yakoob

Aga Khan University, javed.yakoob@aku.edu

Wasim Jafri

Aga Khan University, wasim.jafri@aku.edu

Shahab Abid

Aga Khan University, shahab.abid@aku.edu

Nadim Jafri

Aga Khan University

Muhammad Islam

Aga Khan University

See next page for additional authors

Follow this and additional works at: http://ecommons.aku.edu/

pakistan_fhs_mc_med_gastroenterol

Part of the Digestive System Diseases Commons, Gastroenterology Commons, and the Pathological Conditions, Signs and Symptoms Commons

\section{Recommended Citation}

Yakoob, J., Jafri, W., Abid, S., Jafri, N., Islam, M., Hamid, S., Shah, H. A., Hussainy, A. S. (2003). Candida esophagitis: Risk factors in non-HIV population in Pakistan. World Journal of Gastroenterology, 9(10), 2328-2331.

Available at: http://ecommons.aku.edu/pakistan_fhs_mc_med_gastroenterol/61 
Authors

Javed Yakoob, Wasim Jafri, Shahab Abid, Nadim Jafri, Muhammad Islam, Saeed Hamid, Hasnain Ali Shah, and Akbar S. Hussainy 


\title{
Candida esophagitis: Risk factors in non-HIV population in Pakistan
}

\author{
J aved Yakoob, Wasim Jafri, Shahab Abid, NadeemJ afri, Muhammad Islam, Saeed Hamid, Hasnain A Shah, Akbar S Hussainy
}

Javed Yakoob, Wasim Jafri, Shahab Abid, Nadeem Jafri, Muhammad Islam, Saeed Hamid, Hasnain A Shah, Akbar S

Hussainy, Section of Gastroenterology, Department of Medicine and Pathology, Agha Khan University Hospital, Karachi, Pakistan

Correspondence to: Dr. Javed Yakoob, MBBS, PhD. Section of Gastroenterology, Department of Medicine, Agha Khan University Hospital, Stadium Road, Karachi-74800, Pakistan. yakoobjaved@hotmail.com

Telephone: +92-21-48594661 Fax: +92-21-4934294

Received: 2003-06-05 Accepted: 2003-08-19

\begin{abstract}
AIM: Candida esophagitis is a frequent infection in immunocompromised patients. This study was designed to determine its characteristics in non- human immune deficiency virus (HIV) infected patients attending a teaching hospital.
\end{abstract}

METHODS: Clinical records of all patients coded by international classification of diseases 9th revision with clinical modifications' (ICD-9-CM), with candida esophagitis diagnosed by esophagogastroduodenoscopy (EGD) and histopathology over a period of 5 years were studied.

RESULTS: Fifty-one patients ( 27 males, 24 females, range 21-77 years old and mean age 52.9 years) fulfilled the criteria $(0.34 \%$ of the EGD). The common predisposing factors were carcinoma (OR 3.87, Cl 1.00-14.99) and diabetes mellitus (OR 4.39, Cl 1.34-14.42). The frequent clinical symptoms were retrosternal discomfort, dysphagia and epigastric abdominal pain with endoscopic appearance of scattered mucosal plaques. Another endoscopic lesion was associated with candida esophagitis in $15 \%$ patients.

CONCLUSION: Carcinomas, diabetes mellitus, corticosteroid and antibiotic therapy are major risk factors for candida esophagitis in Pakistan. It is an easily managed complication that responds to treatment with nystatin.

Yakoob J, J afri W, Abid S, Jafri N, Islam M, Hamid S, Shah HA, Hussainy AS. Candida esophagitis: Risk factors in non-HIV population in Pakistan. World J Gastroenterol 2003; 9(10): 2328-2331

http://www.wjgnet. com/1007-9327/9/2328.asp

\section{INTRODUCTION}

Infective esophagitis is a rare disease, affecting mostly immunocompromised patients. Candida esophagitis is one of the most common opportunistic infections in patients with impaired immunity and the most common cause of esophageal disease in patients with acquired immune deficiency syndrome $(\text { AIDS })^{[1]}$. It also occurs in debilitated patients who have received broad-spectrum antibiotics, steroids and immunosuppressants. With the advent of transplantation and AIDS, esophageal infection is now a common medical problem ${ }^{[2]}$. The common infections involving immunocompromised non-human immunodeficiency virus (HIV) infected patients include candida and viral diseases such as cytomegalovirus (CMV) and herpes simplex virus $(H S V)^{[2]}$. Immunocompromised patients who develop esophageal symptoms need to undergo endoscopy to rule out candida esophagitis. It is well recognized that candida esophagitis may coexist with other esophageal disorders in these patients ${ }^{[3]}$. The occurrence of multiple simultaneous processes makes definitive endoscopic examination important ${ }^{[4]}$. Several studies have been carried out in the west for candida esophagitis but it has not been studied before in Pakistan. Incidence of AIDS and HIV prevalence are still very low in Pakistan ${ }^{[5]}$. The purpose of our study was to assess the risk factors associated with candida esophagitis in our patients who came from an area with a low incidence of AIDS.

\section{MATERIALS AND METHODS Patients}

The study was conducted at Agha Khan University Hospital (AKUH) in Karachi, a private Academic Medical Center that offers state of the art medical facilities and is used as a referral center for patients from all over the country for expert opinion and treatment. Karachi is a southern port and the largest metropolitan city in Pakistan with a population of over 11 million. In August 2002 we carried out a retrospective analysis of medical records of all the patients who attended endoscopy unit of gastrointestinal section at the AKUH from January 1997-December 2001 and were diagnosed as candida esophagitis. These patients had undergone endoscopy for symptoms arising from the upper gastrointestinal tract over this period and were diagnosed on the basis of endoscopy and histopathology as candida esophagitis. Clinical symptoms at the time of presentation, diagnosis, drug treatment dosage and duration preceding the symptoms such as nystatin suspension or fluconazole, past history of oral candidiasis, candida esophagitis, neutrophil and lymphocyte counts from complete blood picture, random blood glucose, hepatitis B, C and HIV serology were noted. A lymphocyte count was described as low when it was less than $1.5 \times 10^{9}$ per liter ${ }^{[6]}$. All endoscopic examinations were performed by staff-members of our hospital's gastroenterology section, using an Olympus videoscope GIF x Q 140. Candida esophagitis was diagnosed when characteristic candidal plaques were endoscopically identified and pathological confirmation of yeast forms typical for candida was found in association with an active esophagitis. Case patients were labeled as group A and the control group as group B which consisted of those patients without a diagnosis of candida esophagitis and in whom an endoscopic examination was performed immediately before and after every case patient was examined endoscopically ( 2 controls per case). Therefore, candida esophagitis cases and controls were evaluated by the same medical team using the same diagnostic criteria.

\section{Endoscopy}

To describe the severity of candida esophagitis both in AIDS ${ }^{[7,8]}$ and in non-AIDS populations, a grading scale was described by Kodsi et $a l^{[9]}$ or a modification thereof has been 
used $^{[10]}$. Candida esophagitis was graded as the following: Grade 1 as scattered mucosal plaques involving less than $50 \%$ of the esophageal mucosa, grade 2 as mucosal plaques involving more than $50 \%$ esophageal mucosa, grade 3 as confluent plaque material circumferentially coating at least $50 \%$ of the esophageal mucosa but without luminal impingement, grade 4 as circumferential plaque mat coating at least $50 \%$ of the esophageal mucosa with luminal impingement despite air insufflations. In most cases, an ulcer could be readily distinguished endoscopically by the marked hyperemia and granularity of the ulcer base from the surrounding candida esophagitis.

\section{Histopathology}

At the time of endoscopy, routine biopsies were performed on all endoscopic abnormalities. At least 2 biopsies were performed on each esophageal lesion with standard biopsy forceps. All tissue specimens were submitted for routine histopathology, and stained with hematoxylin-eosin (H-E) and periodic acid-Schiff stains (PAS). In the presence of ulcer tissue, immuno-histochemical staining for $C M V$ and $H S V$ was performed using previously described technique to confirm infection $^{[3]}$. An ulcer was considered secondary to candida esophagitis alone when it was found endoscopically and histopathologically. Fungal organisms compatible with candida were seen in the superficial epithelium, there was an absence of viral cytopathic effect histopathologically, no clinical or endoscopic evidence of gastroesophageal reflex disease or drug-induced esophagitis existed.

\section{Statistical analysis}

Results were expressed as mean \pm standard deviation, median range for all continuous variables (e.g., age) and number (percentage) for categorical data (e.g., gender, diabetes mellitus, steroids, etc) were provided. Univariate analysis was performed using the independent sample $t$-test, Pearson Chisquare test and Fisher exact test when ever appropriate. A $P$ value $<0.05$ was considered as statistically significant. All $P$ values were two sided. Statistical interpretation of data was performed using the computerized software programme SPSS version 10.0 .

\section{RESULTS}

\section{Patients}

During the study period, 15000 upper endoscopies were performed in our endoscopy unit. Fifty-one patients were diagnosed with candida esophagitis on the basis of endoscopic and histopathologic criteria. The age, sex and percentage of inpatients are given in Table 1.

\section{Risk factors}

The common risk factors for candida esophagitis were carcinoma (OR 8.05, $95 \%$ CI 1.91-47.1 and $P=0.001$ ), uncontrolled diabetes mellitus (OR 7.34, $95 \%$ CI 2.26-27.5 and $P=0.001$ ), corticosteroid therapy (OR 6.67, $95 \%$ CI 2.2022.3 and $P=0.001$ ) and antibiotics (OR 4.56, $95 \%$ CI 1.1421.5 and $P=0.02$ ) (Table 2).

\section{Clinical feature}

The clinical details are given in Table 1 . The clinical symptoms in group A were retrosternal discomfort in $39.2 \%$ (20/51) patients, of these $6 / 20$ were associated with dysphagia and $3 / 20$ with epigastric pain. Dysphagia was present in $25.4 \%$ (13/51) and epigastric symptoms in $35.2 \%(18 / 51)$ with only $9 / 18$ describing it as an epigastric pain (Table 1). In control group $\mathrm{B}$, retrosternal discomfort was described in $30.3 \%$ (31/102), dysphagia in $19.6 \%$ (20/102) and epigastric symptoms in 50
$\%(51 / 102)$. These patients responded well to treatment with nystatin or fluconazole, $84.3 \%$ (43/51) and $15.7 \%(8 / 51)$, respectively (Table 1).

Table 1 Details of patients presenting with candida esophagitis and controls

\begin{tabular}{|c|c|c|}
\hline & $\begin{array}{c}\text { Cases } \\
\mathrm{n}=51\end{array}$ & $\begin{array}{c}\text { Control } \\
n=102\end{array}$ \\
\hline \multicolumn{3}{|l|}{ Sex } \\
\hline Male & 27 (53) & $58(57)$ \\
\hline Female & $24(47)$ & $44(43)$ \\
\hline \multicolumn{3}{|l|}{ Age in years (yrs) } \\
\hline Range: & $21-77$ & $19-74$ \\
\hline Mean \pm SD & $52.9 \pm 14.6$ & $50.08 \pm 12.64$ \\
\hline No: \% of In-patients & $34(64)$ & $58(54)$ \\
\hline \multicolumn{3}{|l|}{ Risk factors for candida esophagitis } \\
\hline Steroid therapy & $15(29.4 \%)$ & $6(5.8 \%)$ \\
\hline Diabetes mellitus type 1 and 2 & $14(27.4 \%)$ & $5(4.9 \%)$ \\
\hline $\begin{array}{l}\text { Carcinoma } \\
\text { (e.g. breast, gastric, esophagus) }\end{array}$ & $10(19.6 \%)$ & $3(2.9 \%)$ \\
\hline Broad spectrum antibiotics & $8(15.6 \%)$ & $4(3.9 \%)$ \\
\hline Chronic liver disease & $2(3.9 \%)$ & $6(5.8 \%)$ \\
\hline Tuberculosis & $2(3.9 \%)$ & $1(0.9 \%)$ \\
\hline Ischemic heart disease & - & $26(25.4 \%)$ \\
\hline Peptic ulcer disease & - & $26(25.4 \%)$ \\
\hline Hypertension & - & 20 (19.6\%) \\
\hline Chronic anemia & - & $2(1.9 \%)$ \\
\hline Arthritis & - & $1(0.9 \%)$ \\
\hline Primary Infertility & - & $1(0.9 \%)$ \\
\hline Osteoporosis & - & $1(0.9 \%)$ \\
\hline \multicolumn{3}{|l|}{ Clinical symptoms } \\
\hline Retrosternal discomfort & $20(39.3 \%)$ & 31 (30.3\%) \\
\hline Dysphagia & $13(25.4 \%)$ & 20 (19.7\%) \\
\hline Epigastric symptoms & $18(35.3 \%)$ & $51(50 \%)$ \\
\hline \multicolumn{3}{|l|}{ Endoscopic grading } \\
\hline Grade 1 & 9 & \\
\hline Grade 2 & 19 & \\
\hline Grade 3 & 10 & \\
\hline Grade 4 & 13 & \\
\hline \multicolumn{3}{|l|}{ Treatment } \\
\hline Nystatin & $84.3 \%(43 / 51)$ & \\
\hline Fluconazole & $15.7 \%(8 / 51)$ & \\
\hline
\end{tabular}

Results were expressed as number and percentage, mean \pm standard deviation (SD).

\section{Polymorphonuclear leucocyte and lymphocyte counts}

All of our patients had polymorphonuclear leucocyte count within the normal range, while $33.3 \%$ (17/51) had lymphocyte count below the normal range. These patients were mostly those who were on steroid or antibiotics therapy (Table 3 ).

\section{Endoscopy finding}

The endoscopic appearance of plaques varied in color from yellow to white. With increasing severity, scattered mucosal plaques coalesced circumferentially coating the mucosal surface and impinged into the esophageal lumen. In group A, 9 patients had localized disease, 5 patients had disease more prominent in the distal esophagus than in proximal esophagus, while it involved middle esophagus and middle to distal esophagus equally in 4 patients (Table 1). Esophageal ulceration was noted endoscopically and histopathologically in $3.9 \%(2 / 51)$. In these patients, ulcer was believed to be secondary to candida esophagitis alone, as other etiologies of esophageal ulceration were excluded by testing for $C M V, H S V$ and $H I V$ by serology and immuno-histochemistry. In $15.6 \%$ $(8 / 51)$ of group ' $A$ ' patients, associated endoscopic findings included $7.8 \%(4 / 51)$ with antral gastritis, $1.9 \%$ (1/51) with gastric ulcer, $5.8 \%(3 / 51)$ with duodenitis. In control group B 
esophageal disease was found in $35.3 \%$ (36/102) cases, gastric disease in $38.3 \%(39 / 102)$ cases, and duodenal pathology was seen in $26.4 \%$ (27/102) cases.

\section{Correlation of clinical symptoms and endoscopic feature}

There was no correlation between clinical symptoms and endoscopic findings.

\section{Hepatitis B, C and HIV serology}

HIV serology was negative for hepatitis B, and $9.8 \%(5 / 51)$ were positive for hepatitis $\mathrm{C}$ virus.

\section{Histopathology}

Histopathology revealed varying degrees of hyperplastic squamous mucosa with moderate-severe degree of acutechronic inflammation in the surface epithelium. Mucosal surface was covered with desquamated epithelium and inflammatory necrotic slough. Superficial colonies of candida organism showed non-branching hyphae. In cases of ulcerative esophagitis, intact and focally ulcerated mucosa revealed moderate-severe inflammation, basal cell hyperplasia with non-septate fungal hyphae.

Table 2 Results of univariate analysis of potential risk factors for acquisition of candida esophagitis

\begin{tabular}{lcccc}
\hline Variable & $\begin{array}{c}\text { No. of } \\
\text { cases (\%) }\end{array}$ & $\begin{array}{c}\text { No. of } \\
\text { control (\%) }\end{array}$ & $\begin{array}{c}\text { Odd ratio } \\
(95 \% \mathrm{Cl})\end{array}$ & P value \\
\hline Carcinoma & $10(19.6 \%)$ & $3(2.9 \%)$ & $8.05(1.91-47.1)$ & 0.001 \\
Diabetes mellitus & $14(27.4 \%)$ & $5(4.9 \%)$ & $7.34(2.26-27.5)$ & 0.001 \\
Prior use of steroid & $15(29.4 \%)$ & $6(5.8 \%)$ & $6.67(2.20-22.3)$ & 0.001 \\
Prior use of & $8(15.6 \%)$ & $4(3.9 \%)$ & $4.55(1.14-21.5)$ & 0.02 \\
antibiotics & & & & \\
\hline
\end{tabular}

Table 3 Distribution of low lymphocyte counts in patients presenting with candida esophagitis

\begin{tabular}{lc}
\hline Association & Cases $(n=17)$ \\
\hline Steroids & 6 \\
Antibiotics & 6 \\
Malignancy & 3 \\
Diabetes mellitus & 1 \\
Chronic liver disease & 1 \\
\hline
\end{tabular}

\section{DISCUSSION}

Our study is the first attempt to evaluate the risk factors and endoscopic manifestations of candida esophagitis in Pakistan, an area where AIDS is not endemic. All of our patients diagnosed with candida esophagitis did not have oral thrush. This was similar to a study by Bonacini et al in which 110 HIV positive patients with esophageal symptoms, $38 \%$ of those without oral thrush had candida esophagitis ${ }^{[11]}$. In this study, the patients had oral, intravenous and nebulizer steroid treatment in varying durations and doses of therapy. Steroid levels were not measured on admission. However, steroid therapy was associated with lymphopenia and $33.3 \%$ of our patients presented with a low lymphocyte count ${ }^{[12]}$. Diabetic patients complicated with candida esophagitis had uncontrolled diabetes at the time of presentation, irrespective of its type. Malignancies beside other mechanisms were also associated with esophageal stasis due to mechanical obstruction that predisposes to candida esophagitis ${ }^{[13]}$. However, esophageal obstruction was not a feature in our cases of candida esophagitis associated with malignancies. A high frequency of bacterial or mycotic infections has been reported in $\mathrm{HCV}$-associated membranoproliferative glomerulonephritis and diabetes mellitus due to acquired defects of polymorphonuclear leukocyte (PMN) functions $^{[14,15]}$. In HIV seropositive cases, coexistent candida esophagitis and tuberculosis have been frequently described ${ }^{[16]}$, but in non-HIV immunosuppressed patients, there were few reports of active pulmonary or intestinal tuberculosis associated with candida esophagitis ${ }^{[17]}$.

Epigastric pain has been known to be associated with candida infection ${ }^{[18]}$. In our study, no correlation was found between the symptoms and the endoscopy grade score similar to another study ${ }^{[19]}$. At endoscopy, the presence of classic whitish exudates or plaques should predict candidiasis in at least $90 \%$ of cases, although viral infection occasionally might cause a similar appearance ${ }^{[11]}$. We found that candida esophagitis resulted in typical endoscopic appearances and both characteristic and uniform histopathologic findings. These candida esophagitis patients were treated with either nystatin $5 \mathrm{ml}$ QDS/fluconazole $100 \mathrm{mg}$ a day by mouth for 5 days. None of these candida esophagitis patients was found to be resistant to this treatment. As treatment with fluconazole was expensive, fewer patients were prescribed this medication. Culture for identifying candida species was not carried out, as it would have added cost to the management of disease. The limitation of our study included a small number of patients and a retrospective design. There were few patients with risk factors in the control group B as their stable disease did not predispose them to candida esophagitis (Table 1).

The implications of our study are that in Pakistan candida esophagitis is associated with chronic diseases and those on treatment with corticosteroids and antibiotics are predisposed to it. Patients on these medications need to be monitored and reviewed frequently. Candida esophagitis should be considered early in patients who have been on steroids and antibiotic treatment and presented with upper gastro-intestinal symptoms. Oral candidiasis does not accompany candida esophagitis. Our study showed that candida esophagitis by itself was an easily managed complication. In conclusion, candida esophagitis in Pakistan is more common due to chronic diseases, corticosteroid and antibiotic therapy which impaires the immune system rather than as an AIDS-defining disease. It occurs in the absence of local obstructive lesions and responds to treatment with nystatin and fluconazole.

\section{REFERENCES}

1 Laine L, Boncini M. Esophageal disease in human immunode ficiency virus infection. A rch Intern M ed 1994; 154: 1577-1582

2 Wilcox CM, Karowe MW. Esophageal infections: etiology, diagnosis and management. Gastroenterology 1994; 2: 188-206

3 Schwart DA, Wilcox CM. Atypical cytomegalovirus inclusions in gastrointestinal biopsy specimens from patients with the acquired immunodeficiency syndrome: diagnostic role of in situ nucleic acid hybridization. H um Pathol 1992; 23: 1019-1026

4 Connolly G M, Hawkins D, Harcourt-Webster JN, Parsons PA, Husain OA, Gazzard G. Esophageal symptoms, their causes, treatment and prognosis in patients with the acquired immunodeficiency syndrome. Gut 1989; 30: 1033-1039

5 H yder AA, Khan OA. HIV/ AIDS in Pakistan: the context and magnitude of an emerging threat. J Epidemiol Community $\mathrm{H}$ ealth 1998; 52: 579-585

6 Bagby G C. Disorders of neutrophil production. In: BennetJC, Plum F, eds. Cecil Text book of Medicine. WB Saunders 1996: $908-915$

7 Laine L, Dretler RH, Conteas CN, Tuazon C, Koster FM, Sattler $F$, Squires K, Islam MZ. Fluconazolecompared with ketoconazole for the treatment of candida esophagitis in AIDS. A randomized trial. A nn Intern M ed 1992; 117: 655-660

8 Porro G B, Parente F, Cernuschi M. The diagnosis of esophageal candidiasis in patients with acquired immune deficiency syndrome: Is endoscopy always necessary? A merican J Gastroenterol 1989; 84: 143-146 
9 Kodsi BE, Wickremesinghe PC, Kozinn PJ, Iswara K, Goldberg PK. Candida esophagitis: A prospective study of 27 cases. Gastroenterology 1976; 71: 715-719

10 Wilcox CM, Schwartz DA. Endoscopic-pathologic correlates of candida esophagitis in acquired immunodeficiency syndrome. Dig Dis Sci 1996; 41: 1337-1345

11 Boncini M, Young T, Laine L. The causes of esophageal symptoms in human immunedeficiency virus infection: a prospective study of 110 patients. A rch Intern M ed 1991; 151: 1567-1572

12 Demir G, Derman U, Berkarda B. Haematological effects of pulse steroid therapy. Int J Clin Pharmacol Res 1994; 14: 101-106

13 Rigas B, Spiro HM. Clincal Gastroenterology. M cG raw H ill 1995: $12-15$

14 M azzaro C, Panarello G, Tesio F, Santini G, Crovatto M, Mazzi G, Zorat F, Tulissi P, Pussini E, Baracetti S, Campanacci L, Pozzato G. Hepatitis C Virus risk: a HCV related syndrome. J Intern $M$ ed 2000; 247: 535-545
15 Jirillo E, Greco B, Caradonna L, Satalino R, Pugliese V, Cozzolongo R, Cuppone R, Manghisi OG. Evaluation of cellular immune responses and soluble mediators in patients with $\mathrm{CHCV}$ infection. Immunopharmacol Immunotoxicol 1995; 17: 347-364

16 G eorge J, Hamide A, Das AK, A marnath SK, Rao RS. Clinical and laboratory profile of sixty patients with AIDS: a South Indian study. Southeast A sian J Trop M ed Public H ealth 1996; 27: 686691

17 Hirasaki S. Active intestinal tuberculosis with esophageal candidiasis due to idiopathic CD (+) T-lymphocytopenia in an elderly woman. J Gastroenterol 2000; 35: 47-51

18 Alexander JA, Brouillette DE, Chien MC, YooYK, Tarter RE, Gavaler JS, Van Thiel DH. Infectious esophagitis following liver and renal transplantation. Dig D is Sci 1988; 33: 1121-1126

19 Rodriquez Hernandez H, Reyes Gutierrez E, Elizondo Rivera J. Esophageal candidiasis in AIDS, Clinical, endoscopic and histopathologic analysis of 19 cases. Rev Invest Clin 1991; 43: 124-127

Edited by Wang XL 